\title{
Newton Backward Difference Application for Automating Fertilizer Distribution in Agriculture using Wireless Sensor Networks
}

Santosh T. Warpe, Ravi Kumar Singh Pippal

10.18805/ag.D-5455

\begin{abstract}
Background: The Indian economy and population have been largely influenced by the green revolution which has caused a big change in India. Yet farmers are not able to make full-blown usage of technology to improve crop cultivation. As Indian economy and per capita income, in trade terms, CAPEX (Capital Expenses); is based on agro products, to rejuvenate the demand-supply chain of the food sector, farmers are using fertilizers to increase yield. Due to the excessive use of these puissance fertilizers, soil fertility is adversely impacted. It is hazardous for direct consumption by people. The current study was aimed to optimize the use of fertilizer as per crop requirement using Newton backward difference (NBD) method.

Methods: The experiment was conducted for the last three years (2017-2020) in the Agrotech farm of MIT Academy of Engineering, Pune. The tomato crop was used for taking the readings. Using the NBD, we compared the values between standard, conventional and actual which gives the optimized value and saves the wastage of fertilizer and farmers' burden economically. These NBD can lead to a reduction in the number of sensor nodes in the farm field. The reduction in sensor nodes saves the overall working cost.

Result: The implemented system saves the quantity of nitrogen $(N)$, phosphorus $(P)$ and potassium $(K)$ only by providing the required amount of fertilizer to the crop in comparison with a conventional approach.
\end{abstract}

Key words: Fertilizer, Nitrogen, Phosphorus, Potassium, Wireless sensor networks.

\section{INTRODUCTION}

Balanced and efficient use of fertilizer is vital for better yield. Indian farmers have a very long history of supplementing organic and green manure for soil fertility. The postindependence Indian government foretells increased fertilizer production to increased food grain production. According to the agricultural ministry report, the target to achieve the production of food grain is set to 298.3million tonnes for the year $2020-21$ as compared to the previous year i.e., 2019-20 of 291.95 million tonnes (DOA 15/03/2020, economic times). An additional 6.35 million tonnes has to be achieved from the agricultural land or lands which are occupied by civil works like housing, roads, railways industrial units. Most of the Indian farmers are still struggling to use a balanced and effective method to use the fertilizer to get a better yield. So to overcome this issue in this study authors have used the method NBD which gives accurate fertilizer distribution concerning each crop. The implemented system will take the values from the sensors which are available in the field. These values are then compared with standard values. If the value is less, then the implemented system will decide on the supply of a required amount of $N$ / $\mathrm{P} / \mathrm{K}$ values. The Newton Forward Difference (NFD) method saves the amount of N/P/K by supplying the required value to the crop in comparison with the conventional approach (Warpe et al. 2020). The leaf of $\mathrm{N}$ contents was affected by the cultivar variation. To overcome the problem which occurred due to the cultivar they implemented the multicultivar model useful in monitoring the nitrogen status. Also,
Department of Computer Science Engineering, Ram Krishna Dharmarth Foundation University, Bhopal-462 033, Madhya Pradesh, India.

Corresponding Author: Santosh T. Warpe, School of Computer Engineering and Technology, MIT Academy of Engineering, Alandi (D.), Pune-412 105, Maharashtra, India.

Email: santoshwarpe@gmail.com

How to cite this article: Warpe, S.T. and Pippal, R.K.S. (2022). Newton Backward Difference Application for Automating Fertilizer Distribution in Agriculture using Wireless Sensor Networks. Agricultural Science Digest. DOI: 10.18805/ag.D-5455.

Submitted: 19-07-2021 Accepted: 02-12-2021 Online: 04-03-2022

they provided the recommendation for a variety of strawberry cultivars (Wu et al. 2020). The Sentinel-2 satellite data was used for the mapping of Nitrogen uptake for vegetation indices in three different environmental conditions. The simple ratio red edge had the highest performance among all the methods (Sharifi 2020). Based on the cyber-physical system he developed the Precision Regulation Model of Water and Fertilizer for Alfalfa in agriculture. This model has a biophysical submodel, the computation submodel of water and fertilizer regulation and the interaction of the submodels for both. It interacts with the alfalfa growth and precision regulation of water in the area (Liu et al. 2020).

We can increase the yield of garlic in Bangladesh to meet the demand of the people despite the shortage of land. The experiment named "Pot" was carried out in the net 
situated in the Agriculture University, Bangladesh. Six levels of values for potassium $(\mathrm{K})$ were used. An increase in the garlic yield with the increasing value of $K$ where $k=200 \mathrm{~kg}$ $\mathrm{ha}^{-1}$ was found to be appropriate for getting maximal yield (Jiku et al. 2020). To determine the inflate N2 fixation and soybean seed yield using Rhizobial Immunization and different nitrogen doses they studied and determined the required amount of starter $\mathrm{N}$ application (Getachew et al. 2020). The impact of $P$ application results in increasing and decrease in dissolved organic matter (DOM). An increase in $P$ application has increased the fluorescence index and $\beta / \alpha$ index of DOM whereas a decrease in $P$ application decreases the humification index (Zhi-Jian et al. 2020). Nitrogen $(\mathrm{N})$ plays a major role in the field. In one of the experiments, they show the consistency for the stress of $\mathrm{N}$ on corn yield using the UAV and Cubesat based multispectral sensing (Cai et al. 2019). The Biochar and inorganic fertilizer had the wield effect on rice growth. After 2 years of the onsite experiment the efficiency of agronomic Increased by $140 \%$ and grain nutrient recovery by $191 \%$ (Oladele et al. 2019). Mathematical reenactment outcomes have demonstrated that WSNs with hand-off helped NOMA accomplishes lower blackout possibility and higher aggregate records value, which shows that NOMA strategy can be a competitive upand-comer in every uplink and downlink transmission for WSNs in agribusiness (Zeng et al. 2019). The effect of $\mathrm{K}$ fertilizer application is compared for crop residue and nonresuide parameters. It had no effective influences on soil $\mathrm{C}$ and $\mathrm{N}$ characteristics and soil microbial activities whereas crop residue incorporation promoted $\mathrm{C}$ and $\mathrm{N}$ cycle and accelerated soil microbial activities (Wei et al. 2019). Feather hydrolysates, obtained through the microbial conversion of chicken feathers, improved growth and biomass yield of greenhouse-cultivated lettuce when compared to a reference fertilizer (urea) and different with the aid of products of the poultry agro-enterprise (Lisiane et al. 2019). Our findings highlight the preference to top off $K$ nutrient shares in western Kenya, commonly in fields beneath continuous cultivation that has now not received $\mathrm{K}$ fertilizer or cattle manure. Fertilizing with NPK furnished usually genuine yields for the duration of all fields (Njoroge et al. 2019). Finally, our result suggests that amending soils beneath upland rice cropping machines with rice husk biochar will decrease $\mathrm{N}$ fertilization requirement, whilst sustainably realizing the yield viable of upland rice (Oladele et al. 2019). The purpose of this experiment was to regulate fertilization primarily based on crop needs and soil homes and to reduce the amount of fertilizer in soil without diminishing yield. This method supplied rapid, nondetrimental and simultaneous determination of nitrogen, phosphorus and potassium concentrations in soil fertilizer mixtures (Rawankar et al. 2018).

\section{MATERIALS AND METHODS}

Neither profit nor yield suffers from the balanced use of fertilizer. The imbalanced use of fertilizer value leads to deficiency in expediting the soil nutrients. To make the ideal use of the fertilizer we have used the method NBD.

\section{Newton backward difference}

We know that the conventional approach to distributing fertilizer is a tedious task on the farm. It also wastes fertilizer. With this method, it is never predicted how much fertilizers are utilized, sometimes it is more than crop requirements and sometimes it is less than crop requirements. If the fertilizer use is less than required then crop yield is not proper, if fertilizer uses is more than the requirement, it can lead to soil infertility. To address the issue of accurate usage of the fertilizers as per crop requirement, NBD is the most feasible solution. Along with this, in NBD, as we are working on mean values between spatially apart crops, the node requirement is less.

Ex: If we consider the total farm area 1 acre. In sq/ft it is $40000 \mathrm{sq} / \mathrm{ft}$ which converted to the sq/m leads to $4046 \mathrm{sq} / \mathrm{m}$. The node range can sense the parameter maximum up to 5 $\mathrm{sq} / \mathrm{m}$. 750 to 800 nodes will be required to cover the total farm. It leads to an increase in cost and is difficult to maintain. To reduce these high no. of nodes we can make use of an alternate method that can give us more distance between two nodes with accurate parameters value.

To address the above issue NBD can be used. It is based on an equidistance approach which takes the mean value between the nodes. If we place the position of the nodes apart from each other $100 \mathrm{sq} / \mathrm{m}$ (4046/100) we will require only 40 nodes. If we kept it apart from $50 \mathrm{sq} / \mathrm{m} \mathrm{(4046/}$ $50)$ still it will require only 80 nodes. The requirement of nodes is drastically get reduced if you compare it with the conventional approach.

The task is to find the value of the unknown function $y$ at a given point $x$. The NBD method finds the approximate value of $y$ at a given value of $x$ as shown in Table 1 .

Let the function $y=f(x)$ take the values $y 0, y 1, y 2, \ldots$ corresponding to the values $x 0, x 0+h, x 0+2 h, \ldots$ of $x$. Suppose it is required to evaluate $f(x)$ for $x=x+p h$, where $p$ is any real number. Then we have

$$
\begin{gathered}
E_{p} f(x)=f(x+p h) \\
f\left(x_{n}+p h\right)=E^{p f}\left(x_{n}\right)=(1+\nabla)-p f\left(x_{n}\right)= \\
{\left[1+p \nabla+\frac{p(p+1)}{2 !} \nabla^{2}+\frac{p(p+1)(p+2)}{3 !} \nabla^{3}+\ldots\right] f\left(x_{n}\right)} \\
f\left(x_{n}+p h\right)=f\left(x_{n}\right)+p \nabla f\left(x_{n}\right)+\frac{p(p+1)}{2 !} \nabla^{2} f\left(x_{n}\right)+\frac{p(p+1)(p+2)}{3 !} \\
\nabla^{3} f\left(x_{n}\right)+\ldots+\frac{p(p+1)(p+n-1)}{n !} \nabla^{n} f\left(x_{n}\right)+\text { Error }
\end{gathered}
$$

This is known as Newton's backward difference formula for interpolation, which gives the value of $f(x n+p h)$ in terms of $f\left(x_{n}\right)$ and its leading differences. This formula is also known as the Newton-Gregory Backward difference interpolation formula. 


\section{Algorithm}

$$
\operatorname{NBD}(\nabla y, N v, P v, K v, C v, T v)
$$

1. Start

2. Reads NPK values from the field by using Rapitest 1818 Mini 4 in 1 Soil Tester.

3. Arduino signal conditioner for noise reduction and Analog to Digital conversion for the received data.

4. Save the values in the database.

5. Stow the threshold values.

6. Compute the average of NPK values using NBD.

7. Equate the calculated value with the threshold value.

8. If $\mathrm{Cv}<\mathrm{Tv}$

Start fertilizer distribution

Else

$\mathrm{C} v=>\mathrm{TV}$

Stop fertilizer distribution

9. Repeat steps 1 to 8

Where,

$\mathrm{Xv}$ : Sensor value

Nv: Nitrogen value

$\mathrm{Kv}$ : Potassium value

$\nabla y:$ Current reading

Pv: Phosphorus value

Cv: Calculated value

Tv: Threshold value

\section{Mathematical conversions used}

- 1 hectare $=2.47$ acres

- 1 kilogram $/$ hectare $=0.0001 \mathrm{~kg} / \mathrm{m}^{2}$

- Per day fertilizer distribution calculation=

Total amount of fertilizer used during entire cultivation Total no. of cultivation duration

\section{Experiment setup}

The main focus of the authors is on developing an automated fertilizer distribution system that provides more facilities by reducing farmers' intervention. The system is adequate to dispense the needed N/P/K value based on the brink value.

The experiment was conducted for the last three years (2017-2020) in the Agrotech farm of MIT Academy of Engineering, Pune. The tomato crop was used to take the readings. The multipurpose rapitest 1818 Mini 4 in 1 Soil Tester pH NPK Light Moisture meter is used. The meter takes the available readings from the soil which is combined for $\mathrm{N}, \mathrm{P}$ and $\mathrm{K}$ fertilizer. After every 8 days, readings have been taken for getting the average value. The reading values that we have taken are in analog form. Digital values are wishedfor future computations so that we are the usage of ADC to convert analog values to digital form. It makes use of a $10 \mathrm{bit}$ register for calculating. The sensor unit acquires facts from ADC and is ahead of it to the base station through the microcontroller as shown in Fig 1. Microcontrollers consist of PU, RAM, ROM. The microcontroller works on TTL protocol and our base-station unit works on binary values, so for transmission between micro-controller and basestation, we are the use of Arduino Uno R3. It works on serial communication. The combined value is then stored on the ThingSpeak channel for 24/7 access. There are a total of 2 Master and 4 slave nodes were used for the said setup.

Table 1: Example for NBD.

\begin{tabular}{lcccc}
\hline $\mathrm{x}$ & $\mathrm{Y}$ & $\nabla \mathrm{y}$ & $\nabla^{2} \mathrm{y}$ & $\nabla^{3} \mathrm{y}$ \\
\hline 0 & $\mathrm{y} 0=1.11$ & 1.11 & & \\
1 & $\mathrm{y} 1=2.22$ & 1.11 & 0 & 0 \\
2 & $\mathrm{y} 2=3.33$ & 1.11 & 0 & \\
3 & $\mathrm{y3}=4.44$ & & & \\
\hline
\end{tabular}

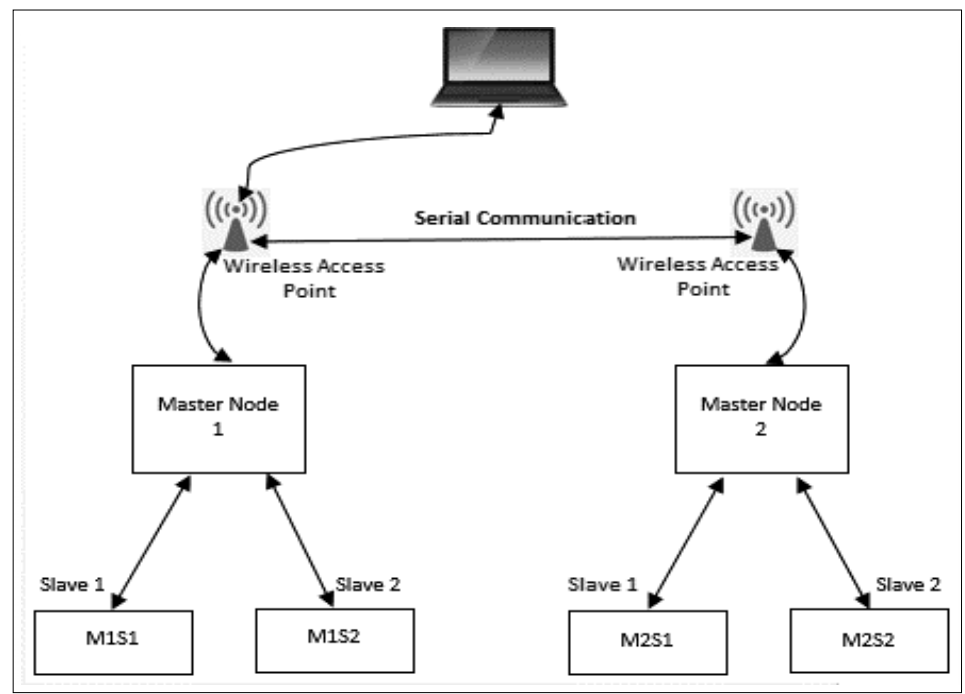

Fig 1: Architecture diagram. 
Two slave nodes namely M1S1 and M1S2 connected to the Master M1. The remaining two slave nodes M2S1 and M2S2 connected to the Master M2. At every node, the processing is done concerning the crop. As we are using NBD interpolation the master nodes are responsible for making all the final computations. The value which is processed at the master node is then compared with the threshold as per the algorithm. If the value is less than the threshold the wall gets "ON" automatically and the required value for the primary fertilizer $(\mathrm{N} / \mathrm{P} / \mathrm{K})$ provided by the system.

\section{RESULTS AND DISCUSSION}

Fig 2 shows the combined values available from Master and Slave nodes. In the backward method, the calculation is done at the master node. The calculated data will then be forwarded to the slave nodes. Fig 3 shows all the readings taken by the sensor during the period. The private channel which was on the ThingSpeak stored all the readings for further processing.
Table 3 shows the weekly comparative utilization of NPK for the tomato crop. It mainly focuses on three important parameters i.e. Standard, Conventional and Actual values. - Standard: Represents the amount of fertilizer required for the tomato crop to have proper development and maximum capitulation.

- Conventional: Represents the distribution of the fertilizer by the farmers during the growing of the tomato crop which does not include any atomization.

- Actual: Represents the required fertilizer supplied to the tomato crop during cultivation using the NBD method.

\section{Comparative graphs}

Fig 4, 5 and 6 shows the comparative graph analysis of the nitrogen, phosphorus and potassium use with respective to Standard, Conventional and Actual values for the said crop. To represent the graphs on the $x$ axis Weeks and $y$-axis values are used.

We are comparing Newton Forward Difference (NFD) and NBD for NPK efficiency. Table 2 represents the standard

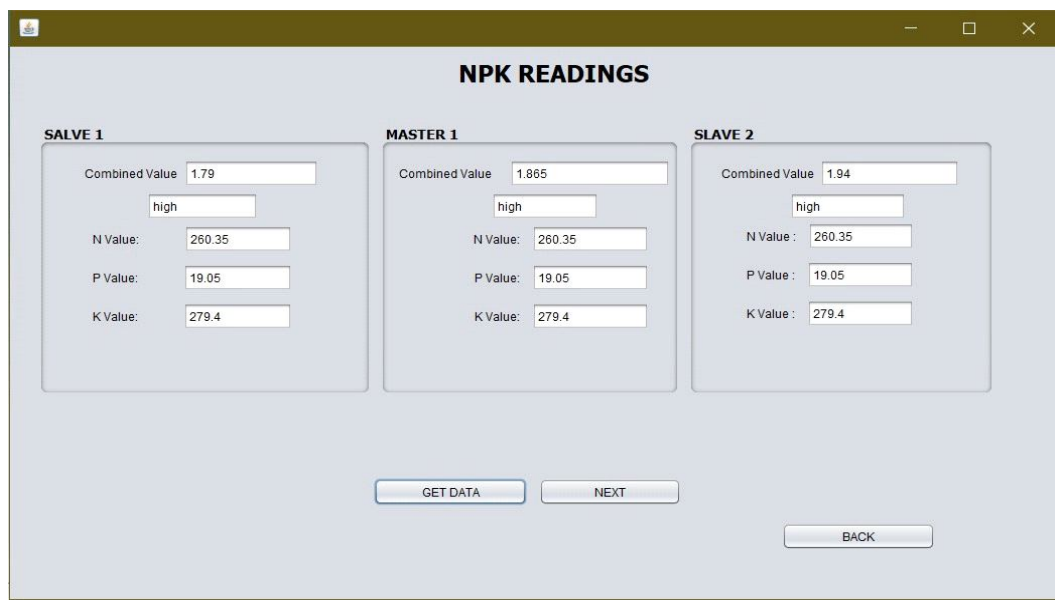

Fig 2: NPK readings for master and slave.

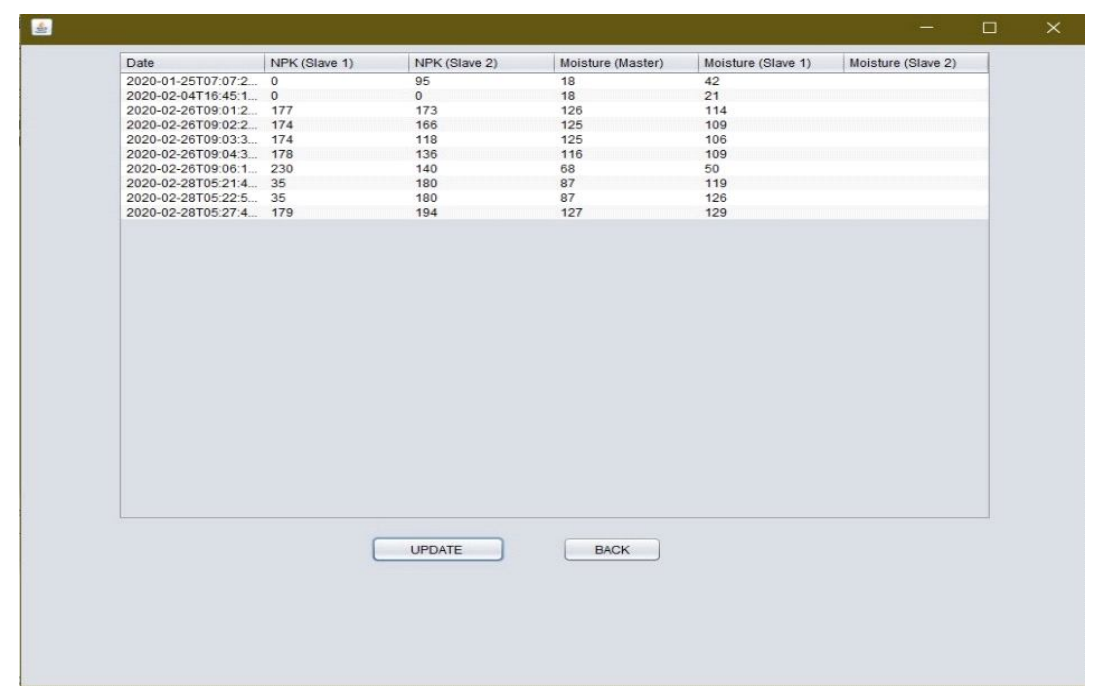

Fig 3: NPK readings stored on ThingSpeak. 


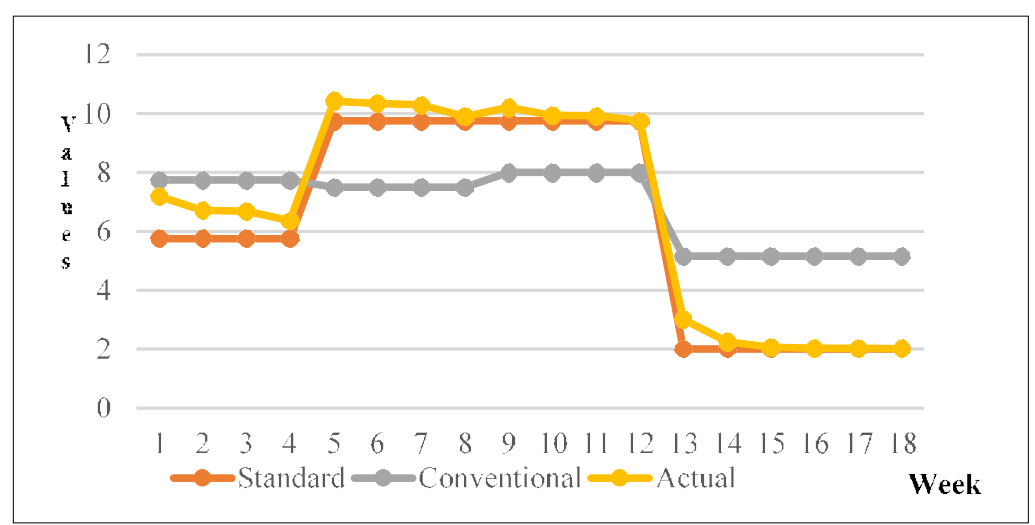

Fig 4: Comparison of nitrogen $(\mathrm{N})$ use for tomato crop in $\mathrm{kg} / \mathrm{ha}$.

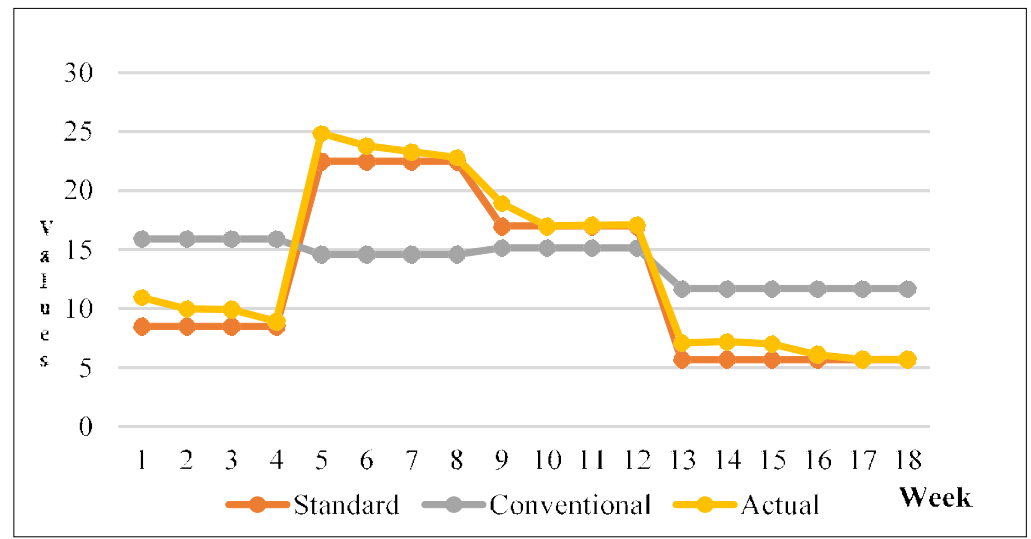

Fig 5: Comparison of phosphorus $(P)$ use for tomato crop in $\mathrm{kg} / \mathrm{ha}$.

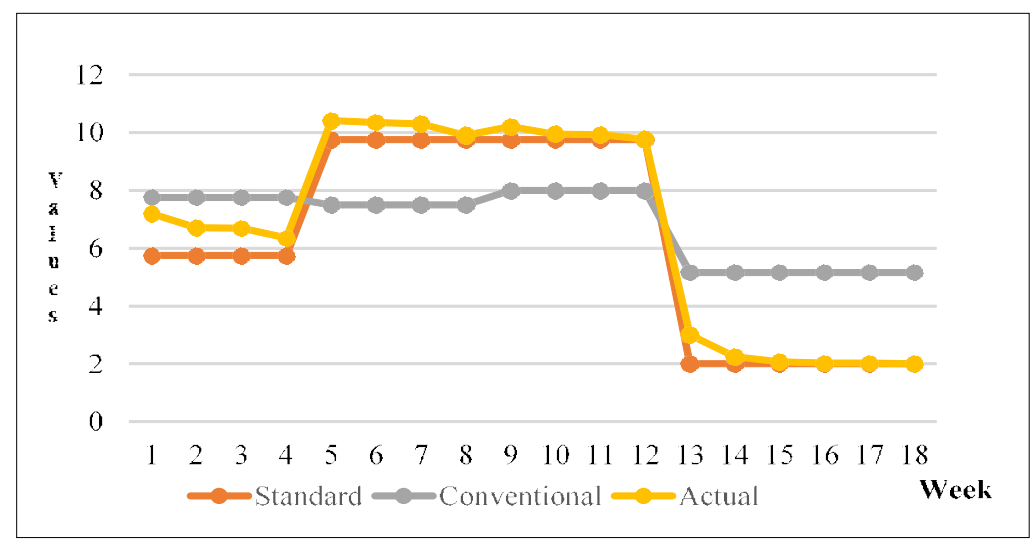

Fig 6: Comparison of Potassium (K) use for tomato crop in $\mathrm{kg} / \mathrm{ha}$.

Table 2: NPK fertilizer distribution table for tomato as follows.

\begin{tabular}{|c|c|c|c|c|c|c|}
\hline $\begin{array}{l}\text { Cultivation period } \\
\text { (In weeks) }\end{array}$ & & $\begin{array}{c}1 \text { to } 28 \\
\text { (4 Weeks) }\end{array}$ & $\begin{array}{c}29-56 \\
\text { (4 Weeks) }\end{array}$ & $\begin{array}{c}57-84 \\
(4 \text { Weeks })\end{array}$ & $\begin{array}{c}85-126 \\
(4 \text { Weeks })\end{array}$ & Total \\
\hline \multirow[t]{2}{*}{ Nitrogen $(\mathrm{N})$} & $\%$ & 15 & 40 & 30 & 15 & 100 \\
\hline & $\mathrm{Kg} / \mathrm{ha}$ & 34 & 90 & 68 & 34 & 225 \\
\hline \multirow[t]{2}{*}{ Phosphorus (P) } & $\%$ & 20 & 35 & 35 & 10 & 100 \\
\hline & $\mathrm{Kg} / \mathrm{ha}$ & 23 & 39 & 39 & 11 & 113 \\
\hline \multirow[t]{2}{*}{ Potassium (K) } & $\%$ & 15 & 30 & 35 & 20 & 100 \\
\hline & $\mathrm{Kg} / \mathrm{ha}$ & 17 & 34 & 39 & 23 & 113 \\
\hline
\end{tabular}




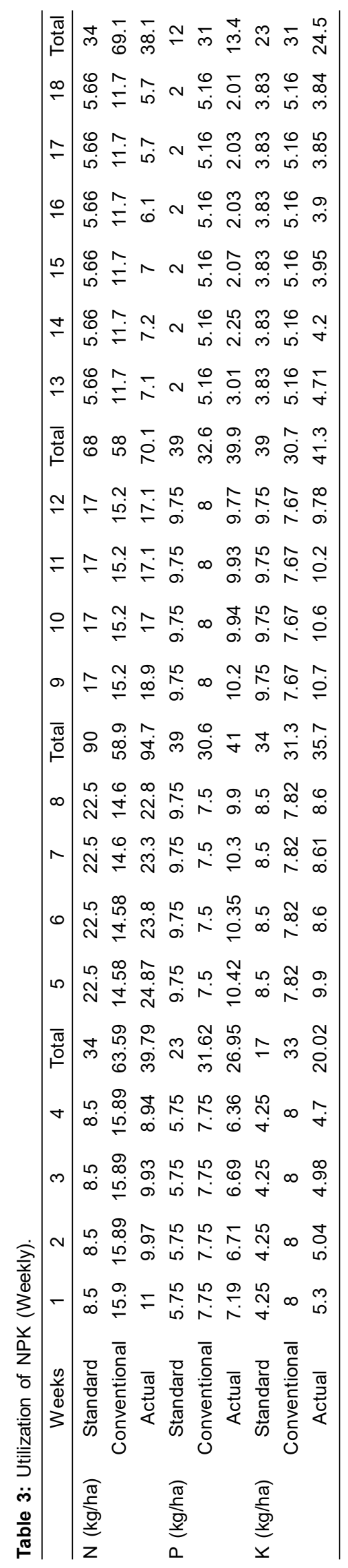

Table 4: The efficiency of NPK.

\begin{tabular}{lcc}
\hline Fertilizer & \multicolumn{2}{c}{ Efficiency (\%) } \\
\cline { 2 - 3 } & NFD & NBD \\
\hline $\mathrm{N}$ & 93.7 & 92.5 \\
$\mathrm{P}$ & 86.38 & 95.58 \\
$\mathrm{~K}$ & 96.09 & 96.11 \\
\hline
\end{tabular}

NPK values for tomato crop which are used to compare with at actual values. Table 4 shows the efficiency of NPK between the two methods. For calculation, we have compared Standard, Conventional and Actual values for the tomato crop. For $\mathrm{N}$ the standard value is 226 , Conventional is 247 and the final value through NFD is 240.35 and for NBD standard value for the said is 226, Conventional is 249.59 and the final value through NBD is 242.71 . For $\mathrm{P}$ the standard value is 113 , Conventional is 124 and the final value through NFD is 128.40 and for NBD standard value for the said crop is 113 , Conventional is 124 and the final value through NBD is 118 . For $\mathrm{K}$ the standard value is 113 , Conventional is 124 and the final value through NFD is 117.42 and for NBD standard value for the said crop is 113 , Conventional is 124 and the final value through NBD is 117.43.NBD is more efficient in the fields where sensor nodes are deployed at a larger distance whereas NFD is more efficient when the distance between nodes is less.

\section{CONCLUSION}

The results show the difference in usage between Conventional and actual methods. In comparison with the conventional approach, NBD saved $2.70 \%, 3.70 \%$ and $3.59 \%$ of nitrogen, phosphorus and potassium respectively. It reduces the cost, manpower and farmers' burden on the farm.

\section{ACKNOWLEDGEMENT}

The authors would like to thank all the authorities of RKDF University, Bhopal and MIT Academy of Engineering, Alandi (D), Pune, India for providing their academic support.

Conflicts of interest: None.

\section{REFERENCES}

Cai, Y., Guan, K., Nafziger, E., Chowdhary, G., Peng, B., Jin, Z., Wang, S. and Wang, S. (2019). Detecting in-season crop nitrogen stress of corn for field trials using UAV- and CubeSat-based multispectral sensing, IEEE Journal of Selected Topics in Applied Earth Observations and Remote Sensing. 12: 12.

Getachew, Z., Gebrehana and Abeble, L. (2020). Response of soybean to Rhizobial inoculation and starter $\mathrm{N}$ fertilizer on Nitisols of Assosa and Begi areas, Western Ethiopia. Springer Open, Environmental Systems Research. 9(14).

Jiku, M.A.S., Alimuzzaman, M., Singha, A., Rahaman, M.A., Ganapati, R.K., Alam, M.A. and Sinha, S.R. (2020). Response and productivity of garlic (Allium sativum L.) by different levels of potassium fertilizer in farm soils. Springer Open Bulletin of the National Research Centre. 44(9). 
Lisiane, S., Rodrigo, R., Elci, G., Gustavo, B., Douglas, K., Daniel, D. (2019). Feather hydrolysate as a promising nitrogen rich fertilizer for greenhouse lettuce cultivation. International Journal of Recycling of Organic Waste in Agriculture (Suppl 1). 8: S493-S499.

Liu, R., Zhang, Y., Ge, Y., Wei, H. and Baiping, S. (2020). Precision regulation model of water and fertilizer for alfalfa based on agriculture cyber-physical system. IEEE Access. 8: 38501-38516.

Njoroge, S., Antonius, G.T., Schut, Ken, E. Giller, Zingore, S. (2019). Learning from the soil's memory: Tailoring of fertilizer application based on past manure applications increases fertilizer use efficiency and crop productivity on Kenyan smallholder farms. European Journal of Agronomy. 105: 52-61.

Oladel, S., Adeyemo, A., Awodun, M., Ajayi, A., Fasina, A. (2019). Effects of biochar and nitrogen fertilizer on soil physico chemical properties, nitrogen use efficiency and upland rice (Oryza sativa) yield grown on an Alfisol in Southwestern Nigeria. International Journal of Recycling of Organic Waste in Agriculture. 8: 295-308.

Rawankar, A., Nanda, M., Jadhav, H., Lotekar, P., Pawar, R., Sibichan, L., Pangare, A. (2018). Detection of N, P, K Fertilizers in Agricultural Soil with NIR Laser Absorption Technique,

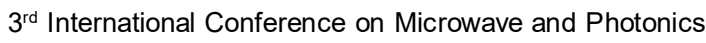
(ICMAP).
Sharifi, A. (2020). Using Sentinel-2 Data to Predict Nitrogen Uptake in Maize Crop. IEEE Journal of Selected Topics in Applied Earth Observations and Remote Sensing. 12: 20.

Warpe S.T., Pippal R.S. (2020). Automated Intensification of Fertilizer Distribution in Agriculture Using Wireless Sensor Network. International Conference on Innovative Trends and Advances in Engineering and Technology (ICITAET). SHEGAON. pp 10-14.

Wei, H., Ning, S., Chaoran, Y., Changqing, Y., Ruixian, L. and Zhiguo, Z. (2019). Comparative effects of crop residue incorporation and inorganic potassium fertilization on soil $\mathrm{C}$ and $\mathrm{N}$ characteristics and microbial activities in a cotton field. Journal of Cotton Research. 2: 24.

Wu, G., Jiang, Q., Bai, Y., Tian, C., Pan, W., Jin, X. and Zhang, B. (2020). Nitrogen status assessment for multiple cultivars of strawberries using portable NIR spectrometers combined with cultivar recognition and multivariate analysis. IEEE Access. 8: 126039-126050

Zeng, H., Longqin, X., Liang, C., Shuangyin, L., Zhijie, L., Jing, W., Xiangli, L. and Lu, W. (2019). Application of non-orthogonal multiple access in wireless sensor networks for smart agriculture. Special section on advances in signal processing for non-orthogonal multiple access. IEEE. 7: 8758287592.

Zhi-Jian, Z., Xian-Zhe, W., Lu-Yi, L., En, H., Xing-Hua, T. (2020). Phosphorus fertilization alters the complexity of paddy soil dissolved organic matter. Journal of Integrative Agriculture. 12: 9. 